\title{
Reasoning about Sexual Assault in Emerging Adults: The Role of Consent
}

JUSTIN KALUZA (1)

\section{CLARE CONRY-MURRAY (i)}

*Author affiliations can be found in the back matter of this article

\section{ABSTRACT}

Emerging adult college students (77 men, 82 women) in the U.S. evaluated consent and the acceptability of a sexual act in hypothetical scenarios which varied the response of the protagonist/victim, the length of the relationship and the gender of the protagonist. Judgments of the acceptability of sexual acts were strongly associated with judgments of consent. Judgments of consent and the acceptability, responsibility for and deserved-punishment for the sexual act differed depending on the victim's responses and relationships lengths. Compared to women, men judged sex after the freezing response to be more acceptable, and the perpetrator to be less responsible and less punish-worthy. In addition, men were less likely than women to label responses where the victim froze as rape. No differences were found between participants in their first years of college compared to their last years of college.

CORRESPONDING AUTHOR:

\section{Clare Conry-Murray}

Saint Joseph's University, US cconrymu@sju.edu

\section{KEYWORDS:}

Sexual assault; gender; moral reasoning; emerging adulthood

TO CITE THIS ARTICLE: Kaluza, J., \& Conry-Murray, C. (2021). Reasoning about Sexual Assault in Emerging Adults: The Role of Consent. Health Psychology Bulletin, 5(1), pp. 124-135. DOI: https:// doi.org/10.5334/hpb.35 
Consent is necessary for a healthy sexual relationship, but what if men and women have different ideas of what consent entails? Research has argued that men and women do indeed have different conceptions of what counts as sexual consent (Hickman \& Muehlenhard, 1999; Sawyer, Pinciaro, \& Jessell, 1998), and a mismatch in assumptions about consent can be devastating since it can result in sexual assault. The current study examines the role of consent in attitudes about sexual assault in dating during the college years because sexual assault is a particular problem during the college years, peaking between the ages of 18-24 (Sinozich \& Langton, 2014), when victims of date-rape and other sexual assaults are especially common.

Consent has been shown to be critical to many moral violations. For example, Conry-Murray and Shaw (2016) found that across two cultures, withdrawal of consent led to a change in participants' evaluations of social acts. This research indicated that consent was seen as necessary, though not sufficient for a social interaction to be judged to be morally permissible. Research on cross-gender interpersonal transgressions shows that consent is seen as key (Shaw, Wainryb, \& Smetana, 2014). Shaw et al. (2014) found that when different gender interactions were seen as entailing coercion, they were judged more negatively.

Legally, consent is also key. Sexual assault according to the U.S. government involves any sexual act that is nonconsensual (Sexual assault, 2019). Rape is one form of sexual assault that is often defined as including "forced penetration" (What Is the Difference Between Rape and Sexual Assault?|Office of Justice Programs, n.d.). Thus, both sexual assault and rape include nonconsent as a key part of what makes these acts criminal. Consent is also key to many college campus' standards for sexual behavior, where some campuses suggest sexual encounters must have affirmative consent. Affirmative consent must be explicit, voluntary and conscious (Ortiz, 2019).

How well do young adults understand consent? Some young adults may have difficulty understanding what constitutes consent, especially when it involves many different types of cues. Consent is an internal state that can be communicated in active and passive ways (Willis et al., 2019). Some people expect verbal cues, including statements of consent or nonconsent, while others may be more likely to pay attention to nonverbal cues, such as moving away or freezing to interpret their partners consent (Beres, Herold \& Maitland, 2004; Hickman \& Muehlenhard, 1999; Sawyer, Pinciaro, \& Jessell, 1999). In addition, people sometimes conflate sexual consent with other concepts such as whether someone wants sex or whether someone receives pleasure from sex (Hills et al. 2021). Consent can also change over the course of an interaction (Beres, Senn, \& McCaw, 2014). These difficulties mean people may not always agree on what constitutes consent, and therefore what constitutes sexual assault.

These difficulties may especially be evident for adolescents who are new to sex. Indeed, a lack of sexual consent comprehension in male participants has been found to be related to self-reported perpetration of sexual aggression (Warren, Swan, \& Allen, 2015). It is possible that sexual assault increases around college age because of increased opportunities combined with a lack of comprehension of consent.

Verbal communication provides a clearer expression of consent than nonverbal communication, and situations entailing sexual intercourse are less likely to be labeled as rape or sexual assault if it utilizes a verbal rather than nonverbal sequence (Lim \& Roloff, 1999). Men and women both rated a direct refusal, or saying "no," as indicating a lack of consent (Hickman \& Muehlenhard, 1999). Other verbal cues can include saying yes, asking if the activity is okay, and telling the partner about a desire to be intimate with them (Beres et al., 2004).

Although some research finds that participants indicate that they would communicate whether they consented to an act with their partner verbally (Jozkowski, Peterson, Sanders, Dennis, \& Reece 2014), they also reported that in determining consent to an activity they would look for nonverbal cues rather than verbal cues. In fact, other research finds that nonverbal behaviors are the most common method of communicating consent for both same-sex (Beres et al., 2004) and heterosexual couples (Hickman \& Muehlenhard, 1999). Active nonverbal cues to consent can include hugging and caressing, physical closeness, smiling, fondling, or touching (Beres et al., 2004). Of nonverbal cues, research indicates that active cues are more likely to be reflective of the intention or internal state of the person, compared to passive cues where action is not taken. In fact, passive cues, like not resisting or not saying no do not reflect consent (Willis et al. 2019).

A lack of consent can also be communicated by moving away, fighting back, or running away. However, research on victims of sexual assault show that one of the most common responses is tonic immobility or freezing (Möller, Bäckström, Söndergaard, \& Helström, 2017). Möller, et al. examines the experiences of women who visited the emergency room within a month after a rape and found that $70 \%$ reported experiencing tonic immobility, indicating that freezing is a very common response to sexual assault. Are college students aware of the problematic nature of assuming consent from immobility or no response?

In the current study we examine how young adults judge different responses, focusing on both verbal and nonverbal responses to a sexual encounter. While past research has examined both verbal and ambiguous responses (e.g. stating "yes" or "no" vs "ambiguous conversations," and no conversation as in Sawyer et al., 1998), we also include tonic immobility in order to assess 
whether young adults recognize this important passive cue as an indication of nonconsent. We also include another nonverbal cue, moving away, to examine whether young adults are sensitive to an active cue to nonconsent.

Although it is not uncommon for women to perpetrate sexual assault, men are more likely to be the perpetrators (Stemple, Flores, \& Meyer, 2017). Therefore, the question of whether men understand that a lack of response is not a sign of consent is an important one. In fact, in a sample of college students, Sawyer, et al. (1999) found that men perceived no significant difference in rape attributions between descriptions of a sexual interactions when one participant engaged in no conversation, ambiguous conversation, and saying yes conditions. In the current study, we examine whether men and women judge verbal and nonverbal methods of communication differently.

In addition, it is possible that other factors are also considered when judging whether consent was provided. Couples who have been in a relationship for longer time periods may be judged to need less explicit levels of consent. Some research has shown that couples that are perceived as having a longer history together are not expected to need explicit verbal consent as much as other couples (Humphreys, 2007). Other studies find no difference based on relationship status (Angelone, Mitchell, \& Grossi, 2015), making it clear that more research on relationship status is needed. We include newly dating couples as well as couples who have dated for a few months, and longer-term couple that have dated for a few years in order to represent a range.

Judgments of consent may also be affected by the sex of the victim (Davies \& Hudson, 2011; Davies, Pollard, \& Archer, 2006; Osman, 2011; Vandiver \& Dupalo, 2012; Whatley \& Riggio, 1993). Men are often seen as initiators of sex while women are seen as gatekeepers (Jozkowski \& Peterson, 2012), which may affect how people view sexual encounters where there is ambiguity about consent by a man compared to a woman. Indeed, previous research (Vandiver \& Dupalo, 2012) has shown that when a rape victim is a man, sexual assault is less likely to be perceived as rape.

There are also differences in how men and women judge sexual assault depending on the gender of the victim. Men judge men who are rape victims to be less believable than women (Vandiver \& Dupalo, 2012) and they show less sympathy toward a man who is a victim (Osman, 2011), especially when he was assaulted by a woman rather than by a man (Davies, Pollard, \& Archer, 2006). Therefore, the current study will examine reasoning about consent in the context of both men and women who are victims of sexual assault.

The current study is focused on college students because the majority of sexual assaults take place within this age range (Sinozich \& Langton, 2014). According to the Department of Justice, women from the ages of
18-24 reported the highest amount of rape and other sexual assaults (Sinozich \& Langton, 2014). We also examine whether development occurs across the college years. Shaw et al. (2014) found that as adolescents age, they pay more attention to consent than their younger counterparts. Yarmey (1985) compared young adults and older adults and found that young adults around age 19 rated sexual assault victims as more to blame than their older counterparts around age 58, but they also rated the perpetrator as more responsible for the assault.

\section{CURRENT STUDY AND HYPOTHESES}

The current study examines emerging adults' reasoning about consent and sexual assault in heterosexual dating relationships. We examine reasoning about consent and sexual assault varying how the victim communicates their consent or lack of consent through their response to sexual activity, including scenarios where a protagonist/ victim says "yes," says "no," freezes or moves away. We also varied the length of time the couple has been dating: weeks, months or years, as well as the gender of the victim. Participants judged the acceptability of these scenarios, whether there was consent, who deserves punishment and who is responsible, if anyone. Finally, they were asked whether the encounter could be called rape, sexual assault, wrong but not rape or sexual assault, or consensual sexual activity. This was included since some research shows that even when men agreed that both physically forced and coerced sex are wrong, participants suggested that these acts should not be considered to be rape (Lynch, Jewell, Golding, \& Kembel, 2017). In addition to examining protagonist/victim response and relationship length for judgements, we also examine age and gender differences to see whether college students mature in their thinking about consent over the course of the college experience and whether gender affects these judgements. Our hypotheses fall into the following categories.

\section{EVALUATIONS OF CONSENT}

We expect victim/participants response, relationship length, protagonist gender, and the gender and age of the participants to all affect evaluations of consent. Specifically, we expect that participants will interpret situations more clearly when victims express their consent or nonconsent verbally rather than nonverbally. We expect that verbal responses of "yes" or "no" will be judged to correspond to consent or nonconsent, respectively, but that nonverbal responses such as moving away and freezing will be judged to be more ambiguous in terms of consent. We expect that judgments of couples that have been dating longer will entail more assumptions of consent. It is expected that there will be differences in evaluating consent and the sexual act based on 
gender. In vignettes with men as protagonists/victims, the sex act will be judged to be more acceptable than when women are protagonists/victims. We also expect gender differences in judgments of consent, where men will be more likely than women to perceive consent. Younger participants will evaluate the vignettes as more consensual than older participants.

\section{EVALUATIONS OF THE SEXUAL ACT}

Evaluations of the sexual act are also expected to be affected by protagonist's/victim's response, relationship length, protagonist gender, and the gender and age of the participants. We expect that nonverbal responses such as moving away and freezing will be judged to be more ambiguous in evaluations of the sexual act than responses that state "yes" or "no." Across all participants, we expect that judgments of couples that have been dating longer will entail greater acceptability of the sexual act. It is expected that vignettes with men as protagonists/victims will be judged to be more acceptable than when women are protagonists/victims. We also expect gender differences in evaluations of the interaction. It is also expected that men will give more positive evaluations of the sexual act than women. Younger participants are also expected to evaluate vignettes as more acceptable.

We also asked for justifications of this question, but we do not include hypotheses for justifications.

\section{ASSOCIATION BETWEEN EVALUATIONS AND JUDGMENTS OF CONSENT}

We expect that perceptions of consent will be related to evaluations of sexual intercourse such that a belief that there was consent will be related to more approval of the sexual act.

\section{JUDGMENTS OF WHO IS RESPONSIBLE AND WHO SHOULD BE PUNISHED}

We combine these hypotheses because they are very similar. We expect both judgments of responsibility and punishment to be affected by the victim/protagonist response, relationship length, protagonist gender, and the gender and age of the participants. Specifically, we expect that judgments of responsibility and punishment will be clear for responses that state "yes" as not responsible or requiring punishment, while "no" responses will indicate the perpetrator is responsible and deserves punishment. However, when protagonists/victims provide nonverbal responses, such as moving away and freezing, judgments of who is responsible and who should be punished will be more ambiguous. We expect that judgments of couples that have been dating longer will involve less responsibility and less punishment assigned to the perpetrator. In vignettes with men as protagonists/victims, the women perpetrators will be judged less responsible and less in need of punishment, compared to when women are victims and men are perpetrators. We expect that participants who are men will give more ambiguous evaluations of the responsibility and punishment for the act than women. Finally, younger participants are expected to judge that the perpetrator is less responsible and should be punished less, compared to judgments by older participants.

\section{LABELING OF SEX ACT}

Given the frequency of the tonic immobility response, we expected gender differences in evaluations of what happened in the interaction that describe a victim freezing. We expect that men will be less likely to label what happened as rape and sexual assault, but more likely to label what happened as neither but still wrong or consensual sexual activity, compared to women.

\section{METHOD \\ PARTICIPANTS}

One hundred and fifty-nine participants (77 men, 82 women) were recruited from an urban private university in a large city in the United States. Approval from the institutional review board was obtained in order to recruit participants through the university's psychology participant pool program and compensate them with partial course credit. Two separate age groups were assessed: 18-20 year old younger emerging adults and 21-23 year old older emerging adults (Means and SDs can be found in Table 1). The sample size was chosen because of convenience related to the number of participants available to us in the participant pool. However, a sensitivity test indicates that our sample size is large enough to detect effects at $f=.30$ with $90 \%$ power in our expected main effect with the largest within-subject factor (protagonist response). Our largest between subject factors each include two levels (age and protagonist gender) and a sensitivity test indicates that our sample size is large enough to detect effects at $d=.37$ with $90 \%$ power for our expected main effects.

\begin{tabular}{llllll}
\hline & \multicolumn{2}{l}{ YOUNGER EMERGING ADULTS } & & \multicolumn{2}{l}{ OLDER EMERGING ADULTS } \\
\cline { 2 - 3 } \cline { 5 - 6 } & MEN & WOMEN & & MEN & WOMEN \\
\hline $\mathrm{N}$ & 36 & 50 & & 41 & 31 \\
\hline Age & $19.58(0.65)$ & $19.18(0.83)$ & & $21.27(0.55)$ & $21.26(0.44)$ \\
\hline
\end{tabular}




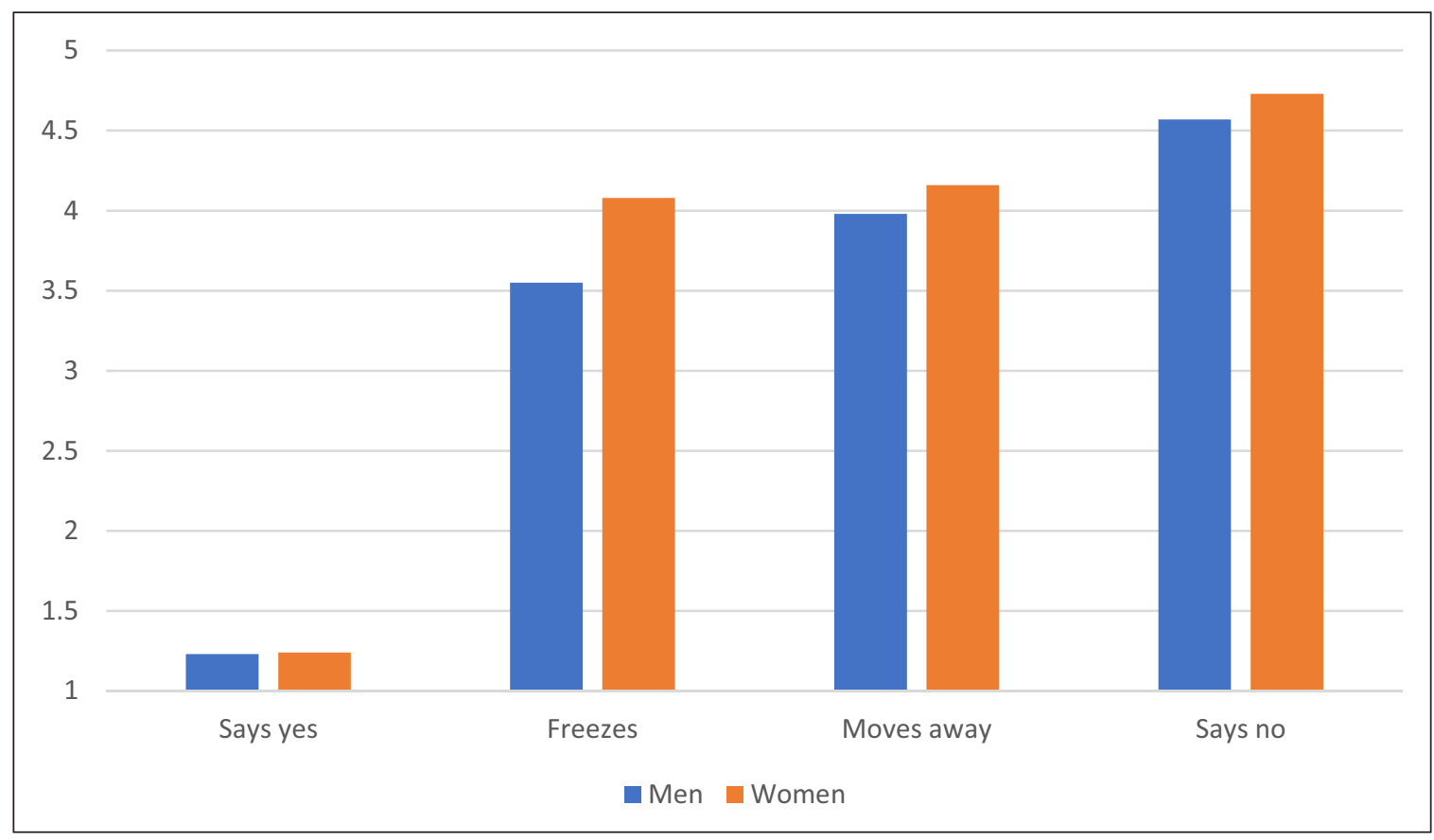

Figure 1 Unacceptability of sex by victim response and participant gender.

Participants were primarily white $(89.7 \%$, Latinx, $4.2 \%$, African American, 4.2\%, Asian, 3\%) and wealthy (57.6\% came from families making over $\$ 100,000 /$ year, with $35 \%$ from families making $\$ 40,000-\$ 100,00$ and $7.2 \%$ from families making under $\$ 40,000)$. Participants were primarily straight $(88.4 \%)$ and cisgender $(95.2 \%)$. Most participants were not in a relationship (64.8\%). Of the participants in this study, 33.3\% reported not knowing anyone personally that has been sexually assaulted, whereas $36.5 \%$ reported knowing one person and $30.2 \%$ reported knowing more than one person.

\section{DESIGN AND PROCEDURE}

Participants completed a questionnaire online that first solicited demographic information (e.g., gender, age, class year, ethnicity). Participants were randomly assigned to either a male or female protagonist/victim condition, in between-subjects design. Participants were then presented with 12 vignettes detailing sexual encounters, with three relationship lengths (dating a few weeks and never previously having had sex together, dating a few months and having had sex several times together before, or dating 2 years and having had sex several times before), and four consent responses (said "yes," said "no," moved away, or froze) varied in a fullybalanced within-subjects design. Thus, the full design included two within-subject factors: 3 (relationship length: a few weeks, a few months, or a few years) $\times 4$ response (said "yes," said "no," moved away or froze), and 3 between-subject factors: protagonist gender (man, women), participant age (18-20, 21-23), and participants gender (women, men).

The vignettes read, "[Protagonist/Victim] and [Perpetrator] have been dating for [a few weeks/a few months/2 years]. They are making out and [Perpetrator] initiates sex. They have [never previously had sex/had sex several times before]. [Protagonist/Victim] [says no/ freezes/moves away/says yes] [and/but] [Perpetrator] continues." Note that not all protagonists in the vignettes were victims since in one condition, the protagonist says "yes" and therefore explicitly verbally consents.

Participants were told that the protagonist/victim and perpetrator have sex (e.g. "Abigail and Michael have sex.") and were asked to judge whether this is okay or not okay ("Is this OK or not OK? Why or why not?") using a 5 -point Likert scale ranging from 1 , definitely okay to 5 , definitely not okay. Participants were asked whether or not the protagonist/victim consented (e.g. "Did Abigail consent?") in the given vignette and answered using a 10-point Likert scale ranging from 1, definitely consented to 10 , definitely did not consent. Then, if the participant responded that the protagonist/victim did not consent they were asked whether or not someone was responsible for what happened. If they responded yes, they were presented with a 5-point scale that asked them who was to blame for the situation (If there was not consent who was responsible for what happened?) ranging from 1 , definitely victim's fault, 3 , both 5 , definitely perpetrators fault. This variable was recoded so that participants who answered that neither was responsible were included as 3 , indicating that 3 meant both or neither were responsible.

Next, participants were asked whether or not they believed someone should be punished. If participants answered yes, they were presented with a 5-point scale that asked them who should be punished for what happened, coded as 1 , definitely victim, 3 , both 5 , definitely perpetrator. This variable was recoded so 
that participants who answered that neither should be punished were included as 3, indicating that 3 meant both or neither should be punished, and allowing the full sample to be included in this analysis.

Finally, participants were presented with a question which stated, "What happened in this situation was...?". Participants then choose either "Rape," "Sexual Assault," Neither Rape nor Sexual Assault, but Still Wrong," or "Consensual Sexual Activity."

The full survey, code, and IRB application are available here: https://osf.io/bk2gx/?view_only=e826fac9026846bdb43 b5fb787d578e1. Recruitment materials were not used, since all data was collected through a subject pool. Unfortunately, we did not get consent to share deidentified data from participants.

\section{RESULTS}

For each dependent variable, a 4(response: freezing, moving, saying no, and saying yes) $\times 3$ (relationship length: a few weeks, a few months, and two years) $x$ 2 (participant gender) $\times 2$ (protagonist gender) 2 (age: early emerging adulthood and older emerging adults) repeated measures analysis of variance (ANOVA) with response and relationship length as repeated measures was conducted. Bonferroni corrections were used for follow-up analyses.

\section{EVALUATIONS OF CONSENT}

A main effect of response, $F(3,447)=1052.490$, $p<.001, \eta_{p}{ }^{2}=.88$ with $90 \%$ CI $[.86 ; .89]$, indicated that all response types were judged differently $(p<.01)$, as Table 2 shows, with consent judged to be strongest when the protagonist/victim said yes, the least likely when the victim said no, and nonverbal responses judged to be ambiguous, especially the freeze response.
A main effect of relationship length, $F(2,298)=21.46$, $p<.001 \eta_{p}{ }^{2}=.13$ with $90 \%$ CI $[.07 ; .18]$, indicated that, as expected, judgments of situations where the couple was in a years-long relationships were more likely to indicate consent than weeks or months, as shown in Table 2. Although there was no significant main effect of gender, $F(1,149)=3.76, p=.054, \eta_{p}{ }^{2}=.03$, the relationship length effect was qualified by a relationship length $\times$ participant gender effect, $F(2,298)=9.60, p<.001, \eta_{p}{ }^{2}=.06$ with $90 \%$ CI $[.02$; .11], which indicated that men evaluated vignettes as being significantly more consensual than women. Follow up tests, $F(1,150)=9.12, p=.003$, $\eta_{\mathrm{p}}{ }^{2}=.06$ with $90 \%$ CI $[.01 ; .13]$, showed that this difference was only significant in vignettes with a relationship length of two years. See Table 3 for means and SD for all relationship length by gender.

No effects of protagonist gender, $F(1,149)=1.66$, $p=.200, \eta_{p}^{2}=.01$, or age, $F(1,149)=.27, p=.607$, $\eta_{p}^{2}=.00$, were found, despite our expectations.

\section{EVALUATIONS OF THE SEXUAL ACTIVITY}

In judgments of whether the sexual activity was judged to be unacceptable, we found a main effect of

\begin{tabular}{lll}
\hline RELATIONSHIP LENGTH & MEN & WOMEN \\
\hline Weeks & 4.42 & 4.24 \\
& $(.81)$ & $(1.00)$ \\
\hline Months & 4.45 & 4.24 \\
& $(.85)$ & $(1.00)$ \\
\hline Years & $4.45^{*}$ & $4.30^{*}$ \\
& $(.85)$ & $(1.11)$ \\
\hline
\end{tabular}

Table 3 Mean (and SDs) Judgments of Perceived Consent. Note: Perceived consent was coded as $1=$ definitely not consent to 10 definitely consent. * Indicates that means in each row differ significantly at $p=.003$.

\begin{tabular}{|c|c|c|c|c|c|c|c|c|c|}
\hline & \multicolumn{4}{|c|}{ PROTAGONIST/VICTIM RESPONSE } & \multicolumn{3}{|c|}{ RELATIONSHIP LENGTH } & \multicolumn{2}{|c|}{ PARTICIPANT GENDER } \\
\hline & FREEZE & $\begin{array}{l}\text { MOVES } \\
\text { AWAY }\end{array}$ & $\begin{array}{l}\text { SAYS } \\
\text { "YES" }\end{array}$ & $\begin{array}{l}\text { SAYS } \\
\text { "NO" }\end{array}$ & WEEKS & MONTHS & YEARS & MEN & WOMEN \\
\hline Perceived consent & $\begin{array}{l}3.53 a \\
(1.90)\end{array}$ & $\begin{array}{l}3.12_{b} \\
(1.78)\end{array}$ & $\begin{array}{l}9.60_{c} \\
(1.14)\end{array}$ & $\begin{array}{l}1.38_{d} \\
(1.00)\end{array}$ & $\begin{array}{l}4.33 \\
(.91)\end{array}$ & $\begin{array}{l}4.34 a \\
(.93)\end{array}$ & $\begin{array}{l}4.55_{b} \\
(1.06)\end{array}$ & $\begin{array}{l}4.54 \\
(.81)\end{array}$ & $\begin{array}{l}4.26 \\
(.99)\end{array}$ \\
\hline Unacceptability & $\begin{array}{l}3.82{ }_{a} \\
(.89)\end{array}$ & $\begin{array}{l}4.08_{b} \\
(.69)\end{array}$ & $\begin{array}{l}1.24 c \\
(.45)\end{array}$ & $\begin{array}{l}4.65 \mathrm{~d}_{\mathrm{d}} \\
(.62)\end{array}$ & $\begin{array}{l}3.54 a \\
(.48)\end{array}$ & $\begin{array}{l}3.43_{b} \\
(.48)\end{array}$ & $\begin{array}{l}3.38_{b} \\
(.60)\end{array}$ & $\begin{array}{l}3.36 a \\
(.44)\end{array}$ & $\begin{array}{l}3.57 \mathrm{~b} \\
(.46)\end{array}$ \\
\hline $\begin{array}{l}\text { Judgments of } \\
\text { responsibility }\end{array}$ & $\begin{array}{l}3.94 a \\
(.72)\end{array}$ & $\begin{array}{l}4.08{ }_{a} \\
(.69)\end{array}$ & $\begin{array}{l}3.02_{b} \\
(.20)\end{array}$ & $\begin{array}{l}4.74 c \\
(.50)\end{array}$ & $\begin{array}{l}4.00 a \\
(.43)\end{array}$ & $\begin{array}{l}3.92_{b} \\
(.45)\end{array}$ & $\begin{array}{l}3.92_{b} \\
(.47)\end{array}$ & $\begin{array}{l}3.86_{a} \\
(.40)\end{array}$ & $\begin{array}{l}4.03_{b} \\
(.40)\end{array}$ \\
\hline $\begin{array}{l}\text { Judgments of } \\
\text { punishment }\end{array}$ & $\begin{array}{l}3.81_{a} \\
(.89)\end{array}$ & $\begin{array}{l}3.93_{b} \\
(.71)\end{array}$ & $\begin{array}{l}2.97{ }^{c} \\
(.28)^{\prime}\end{array}$ & $\begin{array}{l}4.60_{d} \\
(.59)\end{array}$ & $\begin{array}{l}3.90 a \\
(.50)\end{array}$ & $\begin{array}{l}3.79_{b} \\
(.53)\end{array}$ & $\begin{array}{l}3.67 \mathrm{~b} \\
(.45)\end{array}$ & $\begin{array}{l}3.37{ }_{a} \\
(.45)\end{array}$ & $\begin{array}{l}3.56_{b} \\
(.45)\end{array}$ \\
\hline
\end{tabular}

Table 2 Means (and SDs) for judgments by response, relationship length and sex.

Note: Perceived consent was coded as $1=$ definitely not consent to 10 definitely consent. Acceptability was coded from $1=$ definitely OK to 5 definitely not OK; Judgments of responsibility and who should be punished were coded $1=$ definitely the victim 3 neither or both and 5 definitely the perpetrator.

Subscripts that differ within Response, Relationship Length and Gender indicate that means are significantly different at $p<.05$. 
response, $F(3,438)=1448.75, p<.001, \eta_{p}^{2}=.91$ with $90 \%$ CI $[.90 ; .92]$, indicating that all responses were judged differently $(p<.01)$. We also found a main effect of participant gender, $F(1,146)=8.13, p=.005, \eta_{p}^{2}=.05$ with $90 \%$ CI $[.01 ; .12]$, indicating that women judged the act more negatively. These were qualified by a response $\times$ participant gender interaction, $F(3,438)=$ $8.12, p<.001, \eta_{p}{ }^{2}=.05$ with $90 \%$ CI [.02; .09], indicating that women were significantly more likely than men to perceive the sexual act as unacceptable when the victim froze, $F(1,156)=15.81, p<.001, \eta_{p}^{2}=.09$ with 90\% CI [.03; .17], (see Table 4 and Figure 1).

There was a main effect of relationship length, $F(2$, $292)=14.12, p<.001, \eta_{p}{ }^{2}=.09$ with $90 \%$ CI [.04; .14], which indicated that the sexual activity was evaluated as significantly more unacceptable in relationships of a few weeks as compared to relationships of a few months and of 2 years, which did not differ as Table 2 shows.

A main effect for protagonist/victim gender, $F(1,146)$ $=4.47, p=.036, \eta_{p}{ }^{2}=.03$ with $90 \%$ CI [.00; .09], indicated that participants evaluated the sexual act in vignettes with a male protagonist/victim $(M=3.39, S D=0.50)$ as significantly less unacceptable than in vignettes with a female protagonist/victim $(M=3.54, S D=0.40)$, as expected.

No age effects for act evaluations were found, $F(1$, 150) $=.00, p=.993, \eta_{p}^{2}=.00$.

Although we had no hypotheses about justifications for the evaluation of the event, we include frequencies (proportions) in Table 5.

\section{ASSOCIATIONS BETWEEN EVALUATIONS AND JUDGEMENTS OF CONSENT}

Correlations were conducted between composite scores of the different consent conditions for evaluations of consent and act unacceptability. As expected, in all response conditions, consent and unacceptability were negatively correlated, freezing: $r=-.84$ with $95 \%$ CI [-.79, -.88 ], $p<.001$, moves away: $r=-.72$ with $95 \%$ CI [-.64, -.79], $p<.001$, saying no condition: $r=-.79$ with $95 \%$ CI $[-.72,-.84], p<.001$, and saying yes: $r=-.54$ with $95 \%$ CI $[-.42,-.64], p<.001$ indicating that perceptions of a

\begin{tabular}{|c|c|c|c|c|c|c|c|c|}
\hline & \multicolumn{8}{|c|}{ PROTAGONIST/VICTIM RESPONSE } \\
\hline & \multicolumn{2}{|c|}{ FREEZE } & \multicolumn{2}{|c|}{ MOVES AWAY } & \multicolumn{2}{|c|}{ SAYS “YES” } & \multicolumn{2}{|c|}{ SAYS “NO” } \\
\hline & MEN & WOMEN & MEN & WOMEN & MEN & WOMEN & MEN & WOMEN \\
\hline $\begin{array}{l}\text { Perceived } \\
\text { consent }\end{array}$ & $\begin{array}{l}3.98 \\
(1.67)\end{array}$ & $\begin{array}{l}3.11 \\
(2.01)\end{array}$ & $\begin{array}{l}3.19 \\
(1.73)\end{array}$ & $\begin{array}{l}3.05 \\
(1.84)\end{array}$ & $\begin{array}{l}9.66 \\
(1.03)\end{array}$ & $\begin{array}{l}9.54 \\
(1.24)\end{array}$ & $\begin{array}{l}1.41 \\
(.96)\end{array}$ & $\begin{array}{l}1.34 \\
(1.03)\end{array}$ \\
\hline Unacceptability & $\begin{array}{l}3.55^{*} \\
(.84)\end{array}$ & $\begin{array}{l}4.08^{*} \\
(.87)\end{array}$ & $\begin{array}{l}3.98 \\
(.66)\end{array}$ & $\begin{array}{l}4.16 \\
(.69)\end{array}$ & $\begin{array}{l}1.23 \\
(.40)\end{array}$ & $\begin{array}{l}1.24 \\
(.49)\end{array}$ & $\begin{array}{l}4.57 \\
(.68)\end{array}$ & $\begin{array}{l}4.73 \\
(.56)\end{array}$ \\
\hline $\begin{array}{l}\text { Judgments of } \\
\text { responsibility }\end{array}$ & $\begin{array}{l}3.72^{*} \\
(.69)\end{array}$ & $\begin{array}{l}4.15^{*} \\
(.69)\end{array}$ & $\begin{array}{l}4.03 \\
(.67)\end{array}$ & $\begin{array}{l}4.13 \\
(.71)\end{array}$ & $\begin{array}{l}3.02 \\
(.09)\end{array}$ & $\begin{array}{l}3.02 \\
(.27)\end{array}$ & $\begin{array}{l}4.67) \\
(.55)\end{array}$ & $\begin{array}{l}4.80 \\
(.43)\end{array}$ \\
\hline $\begin{array}{l}\text { Judgments of } \\
\text { punishment }\end{array}$ & $\begin{array}{l}3.56^{*} \\
(.63)\end{array}$ & $\begin{array}{l}4.04^{*} \\
(.82)\end{array}$ & $\begin{array}{l}3.80 \\
(.63)\end{array}$ & $\begin{array}{l}4.04 \\
(.77)\end{array}$ & $\begin{array}{l}2.98 \\
(.23)\end{array}$ & $\begin{array}{l}2.97 \\
(.33)\end{array}$ & $\begin{array}{l}4.49 \\
(.64)\end{array}$ & $\begin{array}{l}4.70 \\
(.53)\end{array}$ \\
\hline
\end{tabular}

Table 4 Means (and SDs) for judgments by response and sex.

Note: Perceived consent was coded as 1 = definitely not consent to 10 definitely consent. Unacceptability was coded from $1=$ definitely OK to 5 definitely not OK; Judgments of responsibility and who should be punished were coded $1=$ definitely the victim 3 neither or both and 5 definitely the perpetrator.

* Indicates that means in each row differ significantly at $p<.001$.

\begin{tabular}{lllll}
\hline JUSTIFICATIONS & FREEZE & MOVES AWAY & SAYS “YES” & SAYS “NO" \\
\hline She/he must have changed his/er mind if they had sex & .02 & .01 & .02 & .01 \\
\hline He/she should have known that she/he didn't consent & .32 & .36 & .00 & .07 \\
\hline They should have communicated more & .41 & .33 & .02 & .03 \\
\hline He/she knows what he/she really wants & .03 & .01 & .03 & .01 \\
\hline She/he should have been more clear & .12 & .11 & .01 & .02 \\
\hline She/he was playing hard to get & .01 & .01 & .00 & .00 \\
\hline She/he said no/He/She didn't say yes & .10 & .15 & N/A & .85 \\
\hline She/he said yes & N/A & N/A & .92 & N/A \\
\hline
\end{tabular}

Table 5 Justification for Evaluations of the Interaction.

Note: Participants selected one of these justification choices after evaluating the interaction. 
lack of consent were associated with judgments that the act was more unacceptable.

\section{JUDGMENTS OF WHO IS RESPONSIBLE}

In evaluations of responsibility, there was a main effect of response, $F(3,450)=387.06, p<.001, \eta_{p}{ }^{2}=.72$ with $90 \%$ CI $[.67 ; .75]$, indicating that in the freezing and moving away conditions, the perpetrator was judged as less responsible than in the saying no condition, but more responsible than the saying yes condition. Means and SD are in Table 2. A main effect of participant gender, $F(1,150)=6.60, p=.011, \eta_{p}^{2}=.04$ with $90 \%$ CI $[.02 ; .08]$, indicated that women judged that the perpetrators were more responsible than men, as shown in Table 2. These effects were qualified by a response $x$ participant gender interaction, $F(3,450)=6.91, p<.001$, $\eta_{p}{ }^{2}=.04$ with $90 \%$ CI $[.02 ; .07]$, which indicated that men evaluated the perpetrator as significantly less responsible than women, but only when the victim responded to advances by freezing, $F(1,157)=15.38$, $p<.001, \eta_{p}{ }^{2}=.09$ with $90 \%$ CI $[.03 ; .17]$. Means and SDs are located in Table 4.

There was a main effect of relationship length, $F(2$, $300)=6.45, p=.002, \eta_{p}^{2}=.04$ with $90 \%$ CI $[.01 ; .08]$, which indicated that participants evaluated the perpetrator as significantly more responsible in conditions with a relationship length of a few weeks than in relationships of a few months or of two years in length. There was no significant difference between relationships of a few months and of two years. (Means and SDs are located in Table 2).

No effects of protagonist gender, $F(1,150)=.93$, $p=.336, \eta_{p}^{2}=.01$, or age, $F(1,150)=.83, p=.364$, $\eta_{p}^{2}=.01$, were found for judgments of responsibility.

\section{JUDGMENTS OF WHO SHOULD BE PUNISHED}

In evaluations of who should be punished, there was a main effect of response, $F(3,450)=345.35, p<.001$, $\eta_{p}{ }^{2}=.70$ with $90 \%$ CI $[.66 ; .72]$, which indicated that all responses were judged to deserve different punishment $(p<.05)$ and a main effect for participant gender, $F(1$, $150)=9.26, p=.003, \eta_{p}{ }^{2}=.06$ with $90 \%$ CI $[.01 ; .13]$, which indicated that women judged that more punishment was deserved for the perpetrator. These were qualified by a response $\times$ participant gender interaction, $F(3$, 450) $=8.43, p<.001, \eta_{p}{ }^{2}=.05$ with $90 \%$ CI [.2; .09], which showed that women evaluated perpetrators as significantly more deserving of punishment than men $(p<.001)$ only when the victim responded by freezing. (Means and SDs are located in Table 2).

There was a main effect of relationship length, $F(2$, $300)=10.16, p<.001, \eta_{p}{ }^{2}=.06$ with $90 \%$ CI [.02; .11], which indicated that participants evaluated perpetrators as more deserving of punishment in vignettes with a relationship of a few weeks as compared to a relationship of a few months and of 2 years. There was no significant difference found between relationships of a few months and of 2 years in length. Means and SDs are located in Table 2.

No effects for protagonist gender $F(1,150)=1.10$, $p=.297, \eta_{p}^{2}=.01$, or age, $F(1,150)=.018, p=.894$, $\eta_{p}^{2}=.00$, were found.

\section{LABELS FOR THE INTERACTION}

To assess whether participants judged the sexual activity as rape, the final item which asked the participants "what happened" in each of the situations was recoded into four separate dichotomous variables. Each new variable indicates whether the participant believed the situation to be either rape, sexual assault, neither but still wrong, or consensual or not (coded 1 = endorsed label and $0=$ did not endorse label). A total of four 3 (relationship length: a few weeks, a few months, and 2 years) $\times 2$ (participant gender) repeated measures analysis of variance (ANOVA) were conducted to assess whether participants used each label when the victim responded by freezing. Since all data came from the same question, it was not independent and a Bonferroni correction was applied. For evaluations of rape there was a main effect of participant gender, $F(1,150)=7.93$, $p=.006, \eta_{p}^{2}=.05$ with $90 \%$ CI $[.01 ; .12]$, which indicated that men $(M=.16, S D=.32)$ were significantly less likely to evaluate these vignettes as rape than women $(M=.32, S D=.41)$. For evaluations of neither rape nor sexual assault but still wrong there was a main effect at the corrected significance level of sex, $F(1,150)=6.14$, $p=.013, \eta_{p}^{2}=.04$ with $90 \%$ CI $[.00 ; .10]$, which indicated that men $(M=.58, S D=.40)$ were significantly more likely to evaluate these vignettes as wrong but not rape or sexual assault than women $(M=.41, S D=.43)$. There were no significant differences for evaluations that the interactions were sexual assault or consensual.

\section{DISCUSSION}

In the current study, we found that perceptions of consent were significantly related to acceptability of the sexual interaction across several responses, including verbal responses like saying "yes" or "no" and nonverbal responses including moving away or freezing. At least in judgments of these hypothetical situations, differences in how consent is determined were related to whether the sexual act is deemed unacceptable. Therefore, it is important that participants judged consent differently depending on the protagonists' response, with gender differences found most often in the condition where the protagonist froze, and with longer relationships judged to imply more consent.

More specifically, the largest factor which affected judgements of whether the protagonist consented was how the protagonist/victim responded. Verbally stating 
"yes" was indicative of consent, while verbally saying "no" indicated nonconsent, as expected. Other research has found that verbal communication provides a clearer expression of consent (or nonconsent) than nonverbal communication (Lim \& Roloff, 1999). However, other research shows that emerging adults often use active, nonverbal cues to communicate consent (Willis et al. 2019). Passive responses such as a lack of activity or nonverbal active responses like moving away can indicate nonconsent. In the current study, conditions in which when the victim froze or moved away, were judged as more ambiguous, and judgements of the freezing or moving away and freezing response conditions were significantly different from both the "yes" and "no" verbal response conditions. The two nonverbal responses were also differentiated from each other. Freezing was evaluated as more indicative of consent, acceptability, and less responsibility and less punishment for the perpetrator than either moving away or saying no, indicating that it was judged to be the most ambiguous response condition. Justifications of the evaluations of the sexual interaction for these two responses were also more often references to the need for communications between both people involved, and the need for clarity from the victim, compared to the verbal responses.

The freeze response condition was also the condition with the largest gender differences. The gender differences found in the freeze condition indicate that women are more sensitive to different ways that nonconsent might be communicated compared to men. Similarly, women judged that the sexual act was less acceptable, the perpetrator was more responsible and deserved more punishment in the freeze response conditions. No other responses conditions had significant gender differences. These findings are consistent with research that shows that women are more likely than men to view explicit sexual consent as something that is necessary during intimacy (Humphreys, 2007). These findings are also in line with research that has found that men are more accepting of coercion overall (EmmersSommer \& Allen, 1999).

Past research has found that men are more likely to rely on nonverbal cues to interpret their partners' consent than women (Sawyer, et al., 1999). However, past research has examined nonverbal behaviors such as fighting back, running away, or otherwise explicitly, though nonverbally, giving signs of nonconsent. In the current study we examine very common forms of nonverbal cue that indicates non-consent (Moller, et al., 2017).

While protagonist/victim responses had very large effects, the length of the relationship also influenced perceptions of consent, as well as judgments of the sexual activity. Our findings indicate that sexual activity in longer relationships (a few years) were judged to be more consensual and less deserving of punishment across response conditions, compared to shorter relationships (a few days or a few months). In our study (similar to Humphreys, 2007), the shortest relationships were also described as relationships where the couple had never had sex before. In that case, evaluations of sex were most unacceptable, and perpetrators were seen as most responsible, compared to longer relationships where sex was previously part of the relationship. Humphreys (2007) also found that consent was increasingly not required to be explicit as relationships were more established and included previous sex (a first date, dating three months, a relationship of two years).

Like the findings by response condition, there were gender differences in judgments of sexual activity for different relationship lengths. We found that men indicated that they judged that there was more consent in a relationship of two years than in a relationship of a few weeks or months, while women did not distinguish among the relationship lengths in their judgments of consent. Other research has also found gender differences which indicated that men, as compared to women, have a higher tendency to judge sexual assault with less severity when the level of familiarity and intimacy with the perpetrator increases (Newcombe, et al., 2008).

We examined how the condition describing a victim who froze would be labeled. Men were significantly less likely to evaluate vignettes as "rape" than women, but significantly more likely to evaluate vignettes as "neither rape nor sexual assault but still wrong." This is in line with previous research which has found that men are more accepting of sexual coercion overall (Emmers-Sommer \& Allen, 1999). Although our study did not examine sexual coercion, our results are consistent with EmmersSommer and Allen (1999) in that men were more likely than women to make judgments that could lead to sexual assault.

It was expected that male protagonists/victims would be seen as more likely to consent to sexual activity and therefore sexual activity would be judged to be more acceptable for male protagonists/victims across all conditions. However, only judgments of the acceptability of the sexual act were judged differently depending on the sex of the protagonist. Participants evaluated the sexual act as more acceptable when the victim/protagonist was a man, which is similar to previous research (Vandiver \& Dupalo, 2012), showing that when a victim is a man, sexual assault is less likely to be perceived as rape.

Despite our hypothesis, we found no age differences in reasoning about consent, acceptability of the sexual act, responsibility, or punishment. It was expected that, similar to Yarmey (1985), younger participants would rate the victim as more to blame than older participants, but also rate the perpetrator as more responsible for the assault, but this was not the case. It is possible the college years are too short to allow for significant developmental change. 
A significant limitation is that our participants are primarily white and upper class. Our goal was to focus on the general population of college students in the U.S.; however, many college students in the U.S. are people of color and many are not wealthy. Future research should examine a more representative sample.

Finally, we focus on reasoning and not behavior. However, some research finds that a lack of sexual consent comprehension in men has been found to be strongly related to self-reported perpetration of sexual aggression (Warren, et al., 2015), so it is important to examine both reasoning and behavior. Still, it is difficult to know how perpetrators of sexual assault would reason about consent. The miscommunication model of consent (O’Byrne, Hansen, \& Rapley, 2008) suggests that men may use ambiguous consent information to justify their assault, and to shift the blame back to the woman for not being clear enough in her refusal to engage sexually. The current research does not indicate whether men truly misinterpret consent or whether those who perpetrate sexual assault may be motivated to find justification for their behavior, especially in ambiguous situations, such as when the victim freezes. However, given that freezing is a common response to assault (Möller, et al., 2017), it is important for everyone involved in sexual activity to be sensitive to the idea that a partner who freezes is not consenting.

Future research should examine how understanding of consent affect attitudes about sexual assault. Consent is not always straightforward, and a more nuanced understanding of consent may prepare people for different situations (Graf \& Johnson, 2020), incuidng the ways that consent differs in long-term relationships compared to casual sex. Future research should also examine understandings of coercion as it related to consent to sexual acts. Past research shows that men are perceived to use deception to obtain consent (Jozkowski \& Peterson, 2012). Are people sensitive to the possibility that even a verbal affirmative statement may not be fully informed and based on true information or it may not be fully voluntary?

Overall, we found that consent was strongly related to judgments of the acceptability of sexual acts. Almost all participants judged that consent is clearly necessary, as shown by the very low acceptability judgments when the victim says "no." However, differences in judgments of consent and the acceptability of the sexual act were related to victim responses, and relationships lengths. Gender differences were most frequent in the conditions where the victim responded to sexual advances by freezing. Also known as tonic immobility, freezing is a very common response to sexual assault which is associated with later PTSD and severe depression (Möller, et al., 2017). Compared to women, men judged the freezing response to be more acceptable, and the perpetrator to be less responsible and less punish-worthy. In addition, men were less likely than women to label these encounters as rape, and though they did indicate the encounters were wrong. These findings suggest that instead of teaching women or girls to change their behavior in order to avoid sexual assault, we should be teaching men and boys to more readily recognize signs of non-consent, including the freeze response, and to seek and respect consent.

\section{COMPETING INTERESTS}

The authors have no competing interests to declare.

\section{AUTHOR AFFILIATIONS}

\author{
Justin Kaluza (D) orcid.org/0000-0001-9717-8857
}

Saint Joseph's University, US

Clare Conry-Murray (D) orcid.org/0000-0003-0245-1289

Saint Joseph's University, US

\section{REFERENCES}

Angelone, D. J., Mitchell, D., \& Grossi, L. (2015). Men’s perceptions of an acquaintance rape: The role of relationship length, victim resistance, and gender role attitudes. Journal of Interpersonal Violence, 30(13), 22782303. DOI: https://doi.org/10.1177/0886260514552448

Beres, M. A., Herold, E., \& Maitland, S. B. (2004). Sexual consent behaviors in same-sex relationships. Archives of Sexual Behavior, 33(5), 475-486. DOI: https://doi. org/10.1023/B:ASEB.0000037428.41757.10

Beres, M. A., Senn, C. Y., \& McCaw, J. (2014). Navigating ambivalence: How heterosexual young adults make sense of desire differences. Journal of Sex Research, 51, 765-776. DOI: https://doi.org/10.1080/00224499.2013.792327

Conry-Murray, C., \& Shaw, L. A. (2016). Young adults in the United States and Benin reason about gendered cultural traditions. Social Development. DOI: https://doi.org/10.1111/ sode. 12228

Davies, M., \& Hudson, J. (2011). Judgments toward male and transgendered victims in a depicted stranger rape. Journal of Homosexuality, 58(2), 237-247. DOI: https://doi.org/10.1 080/00918369.2011.540179

Davies, M., Pollard, P., \& Archer, J. (2006). Effects of perpetrator gender and victim sexuality on blame toward male victims of sexual assault. The Journal of Social Psychology, 146(3), 275-291. DOI: https://doi.org/10.3200/ SOCP.146.3.275-291

Emmers-Sommer, T. M., \& Allen, M. (1999). Variables related to sexual coercion: A path model. Journal of Social and Personal Relationships, 16(5), 659-678. DOI: https://doi. org/10.1177/0265407599165006

Graf, A. S., \& Johnson, V. (2020). Describing the "gray" area of consent: A comparison of sexual consent understanding across the adult lifespan. The Journal of Sex Research, 1-14. 
Hickman, S. E., \& Muehlenhard, C. L. (1999). 'By the semimystical appearance of a condom': How young women and men communicate sexual consent in heterosexual situations. Journal of Sex Research, 36(3), 258-272. DOI: https://doi.org/10.1080/00224499.2020. 1765953

Hills, P. J., Pleva, M., Seib, E., \& Cole, T. (2021). Understanding How University Students Use Perceptions of Consent, Wantedness, and Pleasure in Labeling Rape. Archives of Sexual Behavior, 50(1), 247-262. DOI: https://doi. org/10.1080/00224499909551996

Humphreys, T. (2007). Perceptions of sexual consent: The impact of relationship history and gender. Journal of Sex Research, 44(4), 307-315. DOI: https://doi.org/10.1007/ s10508-020-01772-1

Jozkowski, K. N., Peterson, Z. D., Sanders, S. A., Dennis, B., $\&$ Reece, M. (2014). Gender differences in heterosexual college students' conceptualizations and indicators of sexual consent: Implications for contemporary sexual assault prevention education. Journal of Sex Research, 51(8), 904-916. DOI: https://doi.org/10.1080/00224499.20 13.792326

Lim, G. Y., \& Roloff, M. E. (1999). Attributing sexual consent. Journal of Applied Communication Research, 27(1), 1-23. DOI: https://doi.org/10.1080/00909889909365521

Lynch, K. R., Jewell, J. A., Golding, J. M., \& Kembel, H. B. (2017). Associations between sexual behavior norm beliefs in relationships and intimate partner rape judgments. Violence Against Women, 23(4), 426-451. DOI: https://doi. org/10.1177/1077801216642871

Newcombe, P. A., van den Eynde, J., Hafner, D., \& Jolly, L. (2008). Attributions of responsibility for rape: Differences across familiarity of situation, gender, and acceptance of rape myths. Journal Of Applied Social Psychology, 38(7), 1736-1754. DOI: https://doi.org/10.1111/j.15591816.2008.00367.x

O'Byrne, R., Hansen, S., \& Rapley, M. (2008). 'If a girl doesn't say 'no'...': Young men, rape and claims of 'insufficient knowledge'. Journal Of Community \& Applied Social Psychology, 18(3), 168-193. DOI: https://doi.org/10.1002/casp.922

Ortiz, R. (2019). Explicit, voluntary, and conscious: assessment of the importance of adopting an affirmative consent definition for sexual assault prevention programming on college campuses. Journal of health communication, 24(9), 728-735. DOI: https://doi.org/10.1080/10810730.2019.16 66939
Osman, S. L. (2011). Predicting rape empathy based on victim, perpetrator, and participant gender, and history of sexual aggression. Sex Roles, 64(7-8), 506-515. DOI: https://doi. org/10.1007/s11199-010-9919-7

Sawyer, R. G., Pinciaro, P. J., \& Jessell, J. K. (1998). Effects of coercion and verbal consent on university students' perception of date rape. American Journal of Health Behavior, 22(1), 46-53.

Shaw, L. A., Wainryb, C., \& Smetana, J. (2014). Early and middle adolescents' reasoning about moral and personal concerns in opposite-sex interactions. Social Development, 23(4), 784-802. DOI: https://doi. org/10.1111/sode.12076

Sinozich, S., \& Langton, L. (2014). Rape and sexual assault victimization among college-age females, 1995-2013. U.S. Department of Justice, 1-20.

Stemple, L., Flores, A., \& Meyer, I. H. (2017). Sexual victimization perpetrated by women: Federal data reveal surprising prevalence. Aggression and Violent Behavior, 34, 302-311. DOI: https://doi.org/10.1016/j. avb.2016.09.007

Warren, P., Swan, S., \& Allen, C. T. (2015). Comprehension of sexual consent as a key factor in the perpetration of sexual aggression among college men. Journal Of Aggression, Maltreatment \& Trauma, 24(8), 897-913. DOI: https://doi. org/10.1080/10926771.2015.1070232

Whatley, M. A., \& Riggio, R. E. (1993). Gender differences in attributions of blame for male rape victims. Journal of Interpersonal Violence, 8(4), 502-511. DOI: https://doi. org/10.1177/088626093008004005

Yarmey, A. D. (1985). Older and younger adults' attributions of responsibility toward rape victims and rapists. Canadian Journal Of Behavioural Science/Revue Canadienne Des Sciences Du Comportement, 17(4), 327-338. DOI: https://doi. org/10.1037/h0080045

\section{PEER REVIEW COMMENTS}

Health Psychology Bulletin has blind peer review, which is unblinded upon article acceptance. The editorial history of this article can be downloaded here:

- PR File 1. Peer Review History. DOI: https://doi. org/10.5334/hpb.35.pr1 
TO CITE THIS ARTICLE:

Kaluza, J., \& Conry-Murray, C. (2021). Reasoning about Sexual Assault in Emerging Adults: The Role of Consent. Health Psychology Bulletin, 5(1), pp. 124-135. DOI: https://doi.org/10.5334/hpb.35

Submitted: 18 March 2021 Accepted: 24 July 2021 Published: 04 August 2021

COPYRIGHT:

(c) 2021 The Author(s). This is an open-access article distributed under the terms of the Creative Commons Attribution 4.0 International License (CC-BY 4.0), which permits unrestricted use, distribution, and reproduction in any medium, provided the original author and source are credited. See http://creativecommons.org/licenses/by/4.0/.

Health Psychology Bulletin is a peer-reviewed open access journal published by Ubiquity Press.

]u[ ə 